\title{
IGIABA SCEGO Y LA CUESTIÓN DE LA IDENTIDAD EN LOS INMIGRANTES DE SEGUNDA GENERACIÓN
}

\author{
IGIABA SCEGO AND SECOND GENERATION IMMIGRANTS' IDENTITY
}

Sara Velázquez García

Universidad de Salamanca

\section{Resumen:}

Los inmigrantes que se establecen en un país nuevo y desconocido se encuentran entre dos culturas, por lo que su identidad se irá forjando con el tiempo. Por otro lado, los hijos de inmigrantes, o inmigrantes de segunda generación deben elegir si adherirse o no a la cultura del país en el que se encuentran. Las obras de la autora italiana Igiaba Scego tratan la identidad de un inmigrante nacido en Italia a partir de la vida de cuatro jóvenes.

\section{Palabras claves:}

Igiaba Scego, inmigrante, identidad.

\section{Abstract:}

Immigrants who establish in an unknown and new country are between two cultures, therefore their identity will be building as time goes by. On the other hand, immigrants' sons or daughters, or second generation immigrants must choose if they should accept or not the foreign culture. Works by the Italian writer Igiaba Scego are about the identity of an immigrant who was born in Italy from lives of four young women.

\section{KEY WORD:}

Igiaba Scego, immigrant, identity. 


\section{Introducción}

“Somala d'origine, italiana di vocazione" (Scego 2003: 8), con estas palabras define su propia identidad la escritora Igiaba Scego, inmigrante de segunda generación. En los últimos años, países como Italia o España, países cuya condición de receptor de inmigrantes es aún reciente si lo comparamos con otros países europeos como Francia o Alemania, han empezado a hacer uso de esta clasificación. Se utiliza esta expresión para referirse a aquellos niños nacidos en Italia que son hijos de inmigrantes o a aquellos niños que llegaron a Italia en edades previas a la escolarización. En Francia, por ejemplo, se alude a estas personas con la misma expresión "immigrés de seconde génération" o también como "enfants issus de l'immigration" (menores de origen inmigrante)

El menor inmigrante se encuentra a menudo suspendido entre dos mundos y dos culturas: por un lado, todavía forma parte de la cultura de origen y se espera de él que sirva de elemento de continuidad y de vínculo histórico con sus ancestros y, por otro, forma parte de la cultura y del país en el que vive, estudia, se relaciona, crece, interactúa... un país hacia el que también experimenta un fuerte sentimiento de pertenencia.

La costruzione dell'identità etnica dei bambini e delle bambine straniere coinvolge soggetti che appartengono a mondi culturali ed etnici differenti. Ciò implica che, a differenza dei coetanei italiani, ai bambini stranieri o di origine straniera che vivono in Italia, non è concessa la possibilità di avere un'unica identità etnica, proprio perché comunque l'esperienza migratoria, sia diretta che indiretta (cioè esperita dai genitori) rappresenta per il minore un elemento di lacerazione identitaria (Istituto Psicoanalitico per le Ricerche Sociali, 2000)

Se establece, por lo tanto, una complicada relación entre su pasado y el de su familia y el país de origen. El primer escollo surge con la terminología y en este sentido surgen multitud de interrogantes que resumimos a continuación: ¿es justo referirse a ellos como inmigrantes? ¿Cuántas generaciones deberán ser marcadas por tal condición? Quizá sería más apropiado utilizar el término acuñado por Tahar Ben Jelloun que se refiere a ellos como "génération involontaire":

Una generazione destinata a incassare i colpi. Questi giovani non sono immigrati nella società, lo sono nella vita... Essi sono lì senza averlo voluto, senza aver nulla deciso e devono adattarsi alla situazione in cui i genitori sono logorati dal lavoro dall'esilio, cosi come devono strappare i gionn a un avvenire indefinito, avoro e a inventarselo invece che viverlo (Ben Jelloun, 1984))

Según las palabras que recogemos del célebre escritor marroquí, estos jóvenes, a los que define como jóvenes inmigrantes en la vida, no han tenido la oportunidad de elegir, deben adaptarse a una situación que, de alguna manera, sus padres les han impuesto. Otras teorías apuntan a que la noción de inmigrante hace referencia a una situación que permanece al menos durante dos generaciones. A esto se añade un nuevo factor. En el momento en el que los menores forman parte del proceso migratorio la inmigración pierde su carácter transitorio, no es ya aquella inmigración que nuestros países conocieron en los años sesenta y setenta, la del hombre adulto que se trasladaba a otro país o a otro continente para conseguir algo de dinero y una seguridad económica que les permitiera volver a su país pasados unos años y poder comenzar de nuevo.

Los hijos de inmigrantes, por lo tanto, no deberían entrar en la categoría sociológica del inmigrante $y$, sin embargo, la realidad nos muestra algo muy diferente. El menor nacido en territorio italiano adquiere la ciudadanía basándose en la forma jurídica jus soli, sin embargo, incluso en países como Francia, donde tienen una trayectoria más larga en este sentido, este hecho no los convierte automáticamente en nacionales. Y no nos referimos únicamente al hecho de poseer o no un documento que atestigüe y dé fe de su nacionalidad, tiene que ver con la identidad que siente cada persona y la que le hacen sentir las personas que lo rodean.

Por lo tanto, han debido acatar la elección de emigrar hecha por sus padres y ahora son ellos quienes deben hacer frente a otra elección que, de alguna manera, determinará toda su vida: deben elegir entre adherirse a la cultura del país de destino existiendo la posibilidad, de ese modo, de perder sus propias raíces o mantenerse arraigados a las creencias, la cultura y la forma de vida de sus padres. Es sin duda, una elección imposible, y su único camino será el equilibrio entre ambas posturas. Pero, ¿cómo se logra ese equilibrio? ¿Hasta qué punto una persona siente como suya la identidad del país en el que ha nacido o del país de sus orígenes? ¿Hasta qué punto su forma de vida, su cultura, los actos más cotidianos son una segunda piel o se convierten en una máscara que les ayuda a sentirse integrados, "normales"? Esta temática es precisamente la que trata Igiaba Scego en algunos de sus relatos.

\section{Igiaba Scego}

La autora es italiana de nacimiento, romana para ser precisos, hija de padres somalíes que huyeron de su país, otrora colonia italiana, poco después del golpe de estado de 1969 que envolvió al país en una inestabilidad política que aún hoy continúa y que desembocó en una terrible guerra civil, como todas, que aún hoy marca el destino del país. Su padre, Ali Omar Scego, era ministro de Asuntos Exteriores cuando tuvo lugar el golpe de estado de Siad Barre y esto le obligó a abandonar su país junto con su familia. 
Igiaba Scego nacerá algunos años después, en 1974, en Roma, donde sus padres habían buscado refugio. Es licenciada por la Universidad de La Sapienza (Roma) en Literaturas Extranjeras y actualmente dedica la mayor parte de su tiempo a la escritura. Hasta el momento ha publicado numerosos relatos y tres novelas: La nomade che amava Alfred Hitchcock, Rhoda y Oltre Babilonia. Somalia forma parte de todos sus escritos, de alguna manera, esto le hace mantenerse más cercana a sus orígenes, a esos orígenes a los que no ha podido volver físicamente desde que era niña, quizá por eso busca ese reencuentro en sus novelas y relatos. Todas sus novelas y relatos dejan ver un equilibrio entre la sutil frontera que existe entre sus dos culturas y pretende lanzar una mirada sobre ambas desde la distancia y la cercanía con la que vive ambas culturas al mismo tiempo.

La propia autora se expresaba así al respecto en una entrevista concedida a Maria Cristina Mauceri y publicada en la web El-Ghibli.org:

[...] io sono nata a Roma da genitori somali e da subitísimo ho avuto questa scissione, perché a casa vivevo la cultura somala e la religione islamica, parlavo il somalo, mangiavo il cibo somalo. Però fuori, entravo in contatto con la realtà italiana, con la scuola, la televisione, gli amici. Questa scissione faceva parte della mia vita ed è chiaro che questa esperienza sia poi passata nella mia scrittura.

Hemos tomado como modelo dos de esos relatos que hablan precisamente de la identidad del "inmigrante" nacido en Italia y lo que conlleva vivir a caballo entre dos realidades, el enfrentamiento que se produce a veces entre el pasado y el futuro, entre lo que viven en su propia casa y lo que viven en la calle. Ambos relatos están recogidos en un volumen titulado Pecore nere que recoge ocho historias escritas por cuatro jóvenes italianas de orígenes inmigrantes: Gabriella Kuruvilla de padre indio y madre italiana, Ingy Mubiayi (nacida en el El Cairo) de madre egipcia y padre de la antigua República de Zaire, Igiaba Scego de padres somalíes y Laila Wadia de padres indios de orígenes persas y nacida en Bombay

\section{Salsicce}

En el primer relato titulado Salsicce una mañana la protagonista, aparentemente sin razón alguna, decide comprar cinco kilos de salchichas, lo que en principio no presenta nada excepcionalmente raro, a no ser por la cantidad, ante los ojos de un italiano o de un español, pero si pensamos que la protagonista es musulmana el hecho se vuelve algo más extraordinario.

Cuando llega a su casa y se encuentra con todas esas salchichas la pregunta que se hace es "Se mi ingoio queste salsicce una per una, la gente lo capirà che sono italiana come loro? Identica a loro?" Cuestiones más que significativas y cargadas de un importante trasfondo. En el momento de hacerse esta pregunta, advierte qué es lo que le ha suscitado esta agitación y esta necesidad de demostrar al mundo cuánto hay de italiana dentro de ella, si es que algo así puede cuantificarse.

Acaba de ser aprobada en Italia la famosa Legge Bossi-Fini relativa a la inmigración y al asilo, que sustituirá a la ley Turco - Napolitano vigente desde 1998. Nos encontramos en el año 2002, y dicha ley supone una reformulación o una revisión de la anterior que se caracteriza, entre otras cosas, por la exigencia de una serie de requisitos para los extracomunitarios que levantó mucha polémica en tanto en cuanto resultaban, en algunos casos, medidas discriminatorias. Especialmente por cuanto se refiere al caso de las huellas digitales, registro habitual en países como España pero que, en Italia sólo pretendía llevarse a cabo con los inmigrantes presuponiendo de este modo, o al menos según fue observado por muchos de ellos, su posible peligrosidad.

La mia ansia è cominciata con l'annuncio della legge Bossi - Finni: A tutti gli extracomunitari che vorranno rinnovare il soggiorno saranno prese preventivamente le impronte digitali. Ed io che ruolo avevo? Sarei stata un'extracomunitaria, quindi una potenziale criminale, a cui lo Stato avrebbe preso le impronte per prevenire un delitto che si supponeva prima o poi avrei commesso? O un'italiana riverita e coccolata a cui lo Stato lasciava il beneficio de dubbio, anche se risultava essere una pluripregiudicata recidiva? Questa storia delle impronte mi sembrava tutto un errore, lo scarabocchio senza Qunso di un bambino infuriato. Perché umiliare cosi la gente? [ ...] quelle malenza senso di un bambino infuriato. Perché umillare cosi la gente? [...] quelle maledette impronte avevano svegliato in me un demon eche si era assorpito da tempo immemorabile.(VV.AA 20062: 26)

A la protagonista de Salsicce esta noticia le trajo a la cabeza recuerdos de factores que desde siempre le han hecho dudar acerca de su identidad. Si bien es cierto que la protagonista del relato dispone de un pasaporte en el que dice claramente que es italiana, "il mio bel passaporto era Bordeaux e sottolineava a tutti gli effetti la mia nacionalita italiana", no lo es menos que pasó toda su infancia intentando responder a una de esas preguntas inútiles que los mayores se empeñan en hacer a los niños. Si al resto nos preguntaban "¿A quién quieres más, a papá o a mamá?" o cosas de este estilo, para ella la pregunta estrella era "Ami più la Somalia o l'Italia?". Y ¿cómo consigue uno responder a una pregunta así?, una pregunta para la que, sin ninguna duda, no hay respuesta.

A otto anni ogni bambino e vessato da una caterva infinita di domande idiote del tipo «ami più la mamma o più il papà?». Naturalmente il bambino che è un essere intelligente [...] si cuce le labbra e fa finta di non aver capito. Lo stesso capitava a 
me all'età di otto anni! La domanda troglodita che mi facevano era: «Ami più la Somalia o l'Italia?» (VV.AA 20062: 27)

Siendo adulta debe enfrentarse una vez más a esta cuestión, un hecho aparentemente insignificante pero que a la protagonista le llevará a plantearse su propia identidad: ¿es una mujer sin identidad? O por el contrario, ¿es una mujer con múltiples identidades? Cuándo se siente italiana, cuándo somalí, son preguntas que la acompañan desde tiempo atrás. Por ello, un buen día decide comprar cinco kilos de salchichas y llevar a cabo, así un proceso de italianización que la ayude a resolver sus dudas, sin embargo las salchichas acabarán en el cubo de la basura y aceptará que debe convivir con la multiplicidad identitaria, que forma parte de su ser y no puede ponerse una máscara que esconda parte de su propio Yo, que Somalia e Italia forman parte de una misma cosa, que es su persona.

Guardo le salsicce e le getto nell'immondezzaio. Ma come ho potuto solo pensare di mangiarle? Perché voglio negare me stessa, solo per far contenta una signora VELAZQUEZ GARCIA, Sara butterata con la voce da travestito? O far content i sadici che hanno introdotto l'umiliazione delle impronte? Sarei più italiana con una salsiccia nello stomaco? E sarei meno somala? O tutto il contrario? No, sarei la stessa, lo stesso mix. E se questo dà fastidio, d'ora in poi me ne fotterò (VV.AA 20062: 35)

\section{Dismatria}

A Roma la gente corre sempre, a Mogadiscio la gente non corre mai. Io sono una via di mezzo tra Roma e Mogadiscio: cammino a passo sostenuto. Do l'impressione di correre ma sempre camminando (VV.AA 20062: 5)

Así comienza el segundo relato al que queremos hacer referencia en este artículo. "Dismatria", presenta la historia de una familia emigrante llegada desde Somalia formada principalmente por mujeres que se sienten "dismatriate" y es ésta una característica también de la obra de Igiaba Scego, bueno, de la obra y de la cultura: el peso de la figura femenina, y en especial de la materna, en su cultura. Eligen variar el término expatriar porque se sienten privadas de su madre tierra.

Il nostro incubo si chiamava dismatria. Qualcuno a volte ci correggeva e ci diceva: «In italiano si dice espatriare, espatrio, voi quindi siete degli espatriati». Scuotevamo la testa, un sogghigno amaro, e ribadivamo il dismatria appena pronunciato. Eravamo dei dismatriati, qualcuno - forse per sempre - aveva tagliato il cordone ombelicale che ci legava alla nostra madre, alla Somalia. (VV.AA 20062: 11)

Como ella misma dice en un momento del relato se comportaban como todo huérfano que sueña con ver un día a su madre, de ese modo ellas, las mujeres que forman esta familia, sueñan con poder volver un día a Somalia, la tierra de sus orígenes a la que están unidas por un fino hilo similar a un cordón umbilical. Y en esa misma ansia de volver algún día se han negado la posibilidad de tener armarios en su casa italiana, eso significaría un asentamiento y, especialmente, la madre de la protagonista parece no querer sentirse arraigada en un país extraño para ella. Guardan todas sus pertenencias en maletas, preparadas siempre para el día en el que, finalmente, puedan emprender su camino de regreso. Regreso que se presenta difícil, sobre todo porque el regreso a su Somalia, la Somalia que ellas habían dejado atrás, su país tal y como lo conocían ya no existe

Mamma diceva sempre: «Se teniamo tutte le nostre cose in valigia, dopo non ci sarà bisogno di farle in fretta e furia». Il «dopo» sottolineava un qualche tempo non definito nel futuro quando saremmo tornati trionfalmente nel seno di mamma Africa (VV.AA 20062: 10)

Regreso que se presenta difícil, sobre todo porque el regreso a su Somalia, la Somalia que ellas habían dejado atrás, su país tal y como lo conocían ya no existe:

\section{Ma non sarebbe stata la stessa cosa, lo sapevo io e con me tutti gli altri. La Nostra Somalia ormai era morta, defunta, finita. Ma noi, come chi vuole negare la evidenza, facevamo finta che lei $[\ldots]$ si fosse assentata solo per un attimo [...] Ecco perché avevamo tante valigie, ecco perché non compravamo armadi, ecco perché la parola} casa era tabù (VV.AA 20062: 12)

Sin embargo, la protagonista decide romper con esta tradición, avergonzada por un hogar sin armarios que le confiere un aire de rareza, consciente de que la ausencia de armarios la aleja de alguna manera de la cultura en la que viven decide plantar cara a su madre. Está convencida de que quiere una casa propia y con armarios; un lugar que sienta completamente suyo, un lugar en el que sienta que puede echar raíces. El proceso de italianización de la protagonista pasará en este caso por la posesión de armarios, un hecho aparentemente tan banal para quienes vivimos rodeados de ellos se convierte en una condición fundamental en la formación de la identidad de la protagonista.

«Voglio comprarmi casa, mamma. Voglio andare a vivere da sola. Voglio un armadio anche, e non più valigie, mai più». Mamma invecchiò di trent'ann dei dismatriati. Ero una paria ribelle. (VV.AA 20062: 19)

No obstante, cuando decide enfrentarse a su madre y expresarle cuáles son sus intenciones, toda la familia comienza a deshacer sus maletas y, para sorpresa de todos, también lo hace la madre que da una vuelta de tuerca al final del relato. La última maleta que abre guarda una bonita sorpresa, es una maleta cargada de objetos que le 
recordarán a Italia si un día debe abandonarla para regresar a su madre patria, son recuerdos de esa nueva matria que han encontrado en el Bel Paese.

«Che significa?», dicevano i nostri occhi.

«Non mi volevo dimenticare di Roma», disse mamma in un sospiro. E poi sorrise.

Ci guardammo tutti. Sorriso globale. Non lo sapevamo ma avevamo un'altra matria.

(VV.AA 20062: 21)

Una vez más, la autora logra un punto de equilibrio entre ambas realidades, una vez más consigue conciliar sus dos identidades y encontrar ese punto en el que se consigue estabilizar la balanza, un punto, aparentemente, tan difícil de descubrir.

\section{Conclusiones}

Con estos relatos, Igiaba Scego nos muestra la realidad de cada vez más jóvenes que deben lidiar a diario con su propio yo, que buscan continuamente puntos de afirmación de su personalidad, jóvenes que, en mi opinión y pese a esta sociedad que gusta tanto de los encasillamientos y de las preguntas con respuestas cerradas, tienen la enorme fortuna de poder vivir y desarrollar una identidad múltiple, de conocer y vivir diferentes culturas. Aunque, como hemos visto, no es una situación fácil esa duplicidad hace que el inmigrante de segunda generación viva en un precario equilibrio, como hemos dicho ya varias veces, entre sus orígenes y la cultura que vive a diario.

Es necesario tener en cuenta que la mayoría de los problemas que les suscita su identidad vienen marcados por la sociedad en la que viven y que les hace continuamente plantearse estas cuestiones. Quizá, antes que hablar de inmigrantes de segunda generación, como afirma Elisa d'Andrea en su tesis, deberíamos referirnos a ellos como "italianos de primera generación", en tanto en cuanto son personas nacidas en Italia, han vivido el país en su presente y sin embargo acusan la falta de una memoria histórica, porque es una historia de la que no han formado parte sus antepasados, pero una historia de la que ellos ya formarán parte en el futuro.

REFERENCIAS BIBLIOGRÁFICAS

\section{Ben Jelloun, T., Hospitalité française, Paris, Ed. Le Seuil, 1984}

Istituto Psicoanalitico per le Ricerche Sociali, "Integrazione e identità dei minori immigrati”,

I bambini degli immigrati, Editor: CESTIM Centro Studi Immigrazione onlus, 20-09-10,

http://www.cestim.it/argomenti/31italia/rapporti-papers/dossier_migrazioni/parte_4/ identita-minori.htm

Scego, I., La nomade che amava Alfred Hitchcock, Roma, Sinnos Editrice, 2003

---, Rhoda, Roma, Sinnos Editrice, 2004.

---, Oltre Babilonia
VV.AA., Pecore Nere: Racconti, Roma, Editori LaTerza, 2007.

VV.AA., Amori bicolori, Roma, Editori LaTerza, 2008 